\title{
Eficacia incierta del suero equino hiperinmune para la neumonía moderada a severa por COVID-19
}

\author{
Uncertain efficacy of hyperimmune equine serum for moderate to severe COVID-19 pneumonia
}

\section{Comentado de:}

Lopardo G, et al. EClinicalMedicine. 2021 Apr 11:100843. doi: 10.1016/j.eclinm.2021.100843. Epub ahead of print. PMID: $33870149^{1}$

\section{Introducción}

La inmunoterapia pasiva es una alternativa terapéutica para los pacientes con COVID-19. Los anticuerpos policlonales equinos (EpAbs, por sus iniciales en inglés) podrían representar una fuente de anticuerpos neutralizantes escalables contra el SARSCoV-2.

\section{Diseño y lugar}

Se realizó un ensayo clínico controlado, aleatorizado, doble ciego, de fase 2/3 de EpAbs (INM005) contra placebo en pacientes adultos hospitalizados con neumonía por COVID-19 moderada y grave, en 19 hospitales de Argentina.

\section{Participantes}

Se incluyeron pacientes entre 18 y 79 años de edad con prueba de reacción en cadena de la polimerasa (PCR) positiva para el SARS-CoV-2, dentro de los 10 días desde el inicio de síntomas, y que fueran hospitalizados con un diagnóstico de enfermedad COVID-19 moderada o grave.

De manera acorde con la categorización de enfermedades propuesta por el Instituto Nacional de Salud del Reino Unido ${ }^{2}$, se definió como enfermedad moderada a los pacientes que presentaban cualquiera de los signos y síntomas de COVID-19 más evidencia de enfermedad de las vías respiratorias inferiores durante la evaluación clínica o las imágenes y que tenían saturación de oxígeno $(\mathrm{SpO} 2) \geq 94 \%$ respirando el aire ambiente al nivel del mar.

La enfermedad grave se definió en las personas que tenían una $\mathrm{SpO} 2<94 \%$ respirando el aire ambiente al nivel del mar, quienes tenían una relación entre la presión parcial arterial de oxígeno y la fracción de oxígeno inspirado $(\mathrm{PaO} 2 / \mathrm{FiO} 2)<300 \mathrm{mmHg}$, frecuencia respiratoria $>30$ respiraciones por minuto o infiltrados pulmonares $>50 \%$.

Se excluyeron a las mujeres embarazadas o en período de lactancia; las personas con antecedentes de tratamiento con plasma de convalescientes para el SARS-CoV-2; quienes participaron en otro ensayo clínico terapéutico para COVID-19; aquellas con antecedentes de anafilaxia, reacción alérgica grave a sueros equinos $\mathrm{o}$ al contacto o exposición a proteínas de caballo; quienes estaban hospitalizadon en unidades de cuidados intensivos y/o necesitaban ventilación mecánica; quienes tenían una alta probabilidad de muerte por razones clínicas distintas a COVID-19 dentro de los siguientes 30 días o estaba previsto su traslado a otra institución de salud.

\section{Intervención}

Se asignó a los pacientes a recibir dos dosis de INM005 $(n=$ $118)$ o placebo $(n=123)$.

\section{Medición del resultado principal}

El resultado principal fue la mejora en al menos dos categorías en la escala clínica ordinal ${ }^{3}$ desarrollada por la Organización Mundial de la Salud (OMS) en el día 28 (ClinicalTrials.gov número NCT04494984).

\section{Resultados}

La mediana de edad de los participantes fue de 54 años; $65,1 \%$ era de sexo masculino y $61 \%$ tenía enfermedad moderada al inicio del estudio. La mediana de tiempo desde el inicio de los síntomas de COVID-19 hasta la administración de la primera dosis del producto de investigación fue de 6 días (intervalo intercuartilo, de 5 a 8 días).

Al día 28 no se observaron diferencias significativas entre los grupos en el desenlace principal: diferencia de riesgo (DR) $5,28 \%$; Intervalo de Confianza (IC) del $95 \%-3,95$ a 14,50; pvalor $=0,15$. La variación general en el estado clínico durante el período de seguimiento de 28 días fue más favorable en el grupo que recibió INM005. La mejoría en al menos dos categorías en la escala clínica ordinal de la OMS fue significativamente mayor en los participantes del grupo INM005 en los días 14 y 21 de seguimiento. Además se observó una diferencia significativa en el tiempo hasta la mejora en al menos dos categorías del estado clínico o el alta hospitalaria; que fue de $14,2( \pm 0,7)$ días en el grupo INM005 y 16,3 $( \pm 0,7)$ días en el grupo placebo (hazard ratio $[H R] 1,31$; IC $95 \% 1$ a 1,74). Los análisis de subgrupos preespecificados mostraron un efecto más pronunciado de la intervención sobre los pacientes graves y sin respuesta de anticuerpos al inicio del estudio. La mortalidad global a los 28 días fue $9,1 \% ; 6,8 \%$ en el grupo INM005 y del $11,4 \%$ en el grupo placebo (DR 0,57; IC $95 \% 0,24$ a 1,37). Los eventos adversos de especial interés fueron leves o moderados, y no se reportó anafilaxia.

\section{Conclusiones}

A pesar de no haber alcanzado el criterio de valoración principal, se observó una mejoría clínica de los pacientes hospitalizados con neumonía por SARS-CoV-2, particularmente en aquellos con enfermedad grave.

Fuente de financiamiento/Conflicto de interés de los autores: Este estudio fue financiado por Inmunova S.A. y becas de los Ministerios de Ciencia y Producción de Argentina. Algunos de los autores recibieron subvenciones otorgadas por el Ministerio de Desarrollo Productivo y la Agencia Nacional de Promoción de la Investigación, el Desarrollo Tecnológico y la Innovación del Ministerio de Ciencia, Tecnología e Innovación, otros recibieron reembolsos por su participación en el ensayo clínico como investigadores del estudio, honorarios personales o fondos de Inmunova u otras compañías farmacéuticas, que se encuentran detallados en el artículo original. 


\section{Comentario}

Desde el inicio de la pandemia producida por el SARS-CoV-2 se han evaluado numerosas intervenciones con el propósito de prevenir o tratar la enfermedad, aunque pocas terapéuticas han demostrado ser útiles hasta el momento. El posible uso de la inmunoterapia pasiva ha sido sólidamente planteado, y Argentina ha tenido importantes y exitosas experiencias en su utilización contra otras enfermedades. Sin embargo, un estudio multicéntrico reciente que evaluó el uso de plasma de convalesciente en un grupo de pacientes similares no obtuvo beneficios clínicos importantes ${ }^{4}$.

Este ensayo intenta contestar una pregunta relevante: ¿el tratamiento con suero equino hiperinmune es eficaz y seguro en pacientes con neumonía moderada a severa por COVID-19? Sin embargo, no presenta el poder suficiente para evaluar desenlaces críticos en pacientes hospitalizados por COVID-19. Sólo ocho pacientes en la rama intervención y 14 en la rama control fallecieron, mientras que 16 pacientes en la rama intervención y 25 en la rama placebo alcanzaron el desenlace compuesto de requerimiento de ventilación invasiva o cuidados en una unidad cerrada. De esta forma, la certeza en el efecto del suero equino hiperinmune sobre desenlaces críticos resulta muy baja.

En relación con otros desenlaces evaluados, el ensayo reportó una posible mejoría en la velocidad en la que los pacientes mejoraron los síntomas o fueron externados (HR 1,31; IC $95 \% 1$ a 1,74; evidencia de baja certeza dada por la imprecisión de la estimación), pero no se observó una diferencia en la proporción de pacientes externados a los 28 días (105/118 en la rama intervención y 103/123 en la rama control). Por otro lado, no fue reportado un incremento en el riesgo de eventos adversos severos. Podría concluirse que si bien el suero equino hiperinmune podría asociarse a beneficios, el estudio resumido no tiene el poder suficiente para confirmarlos ni para cuantificar la magnitud de los mismos.

Por último, cabe destacar que el suero equino hiperinmune tiene un costo económico que, dada la situación de nuestro país, el tamaño de la población a tratar y lo heterogéneo de la posibilidad de cobertura, hace pensar en una seria barrera en el acceso de esta terapéutica ${ }^{5}$. Por todo esto, consideramos que el siguiente paso debería ser la realización de un estudio con poder suficiente para confirmar o descartar los potenciales beneficios asociados al uso de suero equino en pacientes hospitalizados por COVID-19 para determinar si su utilización debe o no ser implementada en el manejo de estos pacientes.

\section{Conclusiones de los comentadores}

Hasta el momento, el suero equino hiperinmune no ha demostrado ser eficaz en el tratamiento de la neumonía moderada a severa por COVID-19. Es necesaria más información proveniente de estudios adecuadamente diseñados para confirmar o descartar y, eventualmente, cuantificar, los potenciales beneficios que se sugieren en la publicación analizada.

Federico Bottaro [ Grupo CIERTO (Club interhospitalario de lectura crítica para recomendar basados en pruebas); Servicio de Clínica Médica, Hospital Británico. febottaro@hotmail.com ]

Hugo N. Catalano [ Grupo CIERTO (Club interhospitalario de lectura crítica para recomendar basados en pruebas); Servicio de Clínica Médica, Hospital Alemán. hcatalano@fmed.uba.ar ]

Ariel Izcovich [ Grupo CIERTO (Club interhospitalario de lectura crítica para recomendar basados en pruebas); Servicio de Clínica Médica, Hospital Alemán. ariel.izcovich@gmail.com ]

Javier Pollan [ Grupo CIERTO (Club interhospitalario de lectura crítica para recomendar basados en pruebas); Servicio de Clínica Médica, Hospital Italiano de Buenos Aires. javier.pollan@hospitalitaliano.org.ar ]

Matías Tisi Baña [ Grupo CIERTO (Club interhospitalario de lectura crítica para recomendar basados en pruebas); Servicio de Clínica Médica, Hospital Austral, Pilar.mtisibana@gmail.com ]

Bottaro F, Caruso D, Catalano HN, Izcovich A, Pollan J, Tisi Baña M. Eficacia incierta del suero equino hiperinmune para la neumonía moderada a severa por COVID-19. Evid Actual Pract Ambul. 2021;24(2):e002121. Comentado de: Lopardo G, et al. RBD-specific polyclonal F(ab') 2 fragments of equine antibodies in patients with moderate to severe COVID-19 disease: A randomized, multicenter, double-blind, placebo-controlled, adaptive phase 2/3 clinical trial. EClinicalMedicine. 2021 Apr 11:100843. doi: 10.1016/j.eclinm.2021.100843. Epub ahead of print. PMID: 33870149

\section{Referencias}

1. Lopardo G, Belloso W, Nannini HE, et al. RBD-Specific Polyclonal F(ab') 2 Fragments of Equine Antibodies in Patients with Moderate to Severe COVID-19 Disease: A Randomized, Double-Blind, Placebo-Controlled, Adaptive Phase 2/3 Clinical Trial. EClinicalMedicine. $2021 ; 34: 100843$. Available from: 10.1016/j.eclinm.2021.100843;https://ssrn.com/abstract=3768544.

2. National Institutes of Health. Clinical Spectrum of SARS-CoV-2 Infection; 2021. Available from: https://www.covid19treatmentguidelines.nih.gov/ overview/clinical-spectrum/ [Last access: 2021-04-29].

3. World Health Organization. novel Coronavirus COVID-19 Therapeutic Trial Synopsis. Geneva, Switzerland: World Health Organization; 2020. Available from: https://www.who.int/blueprint/priority-diseases/key-action/COVID-19_Treatment_Trial_Design_Master_Protocol_synopsis_ Final 18022020.pdf.

4. Simonovich VA, Pratx LB, Scibona P, et al. A Randomized Trial of Convalescent Plasma in Covid-19 Severe Pneumonia. A Randomized Trial of Convalescent Plasma in Covid-19 Severe Pneumonia. 2021;384(7):619-629. Available from: 10.1056/nejmoa2031304;https://dx.doi.org/10.1056/ nejmoa2031304. 
5. Actualizaciones basadas en evidencia COVID-19. Inmunoterapia pasiva con anticuerpos policlonales equinos (suero equino hiperinmune) para el tratamiento de pacientes con COVID-19. Informe de Evaluación de Tecnologías Sanitarias COVID N02; 2021. Available from: https://www.argentina. gob.ar/sites/default/files/informe-rapido-covid-19-n2-suero-equino.pdf. 